\title{
Business process development with the application of simulation technique
}

\author{
L. PUSZTAI, B. KocSI, I. BUdAI \\ University of Debrecen, Faculty of Engineering, Department of Engineering Management and Enterprises, \\ pusztai.laszlo@inf.unideb.hu \\ University of Debrecen, Faculty of Engineering, Department of Engineering Management and Enterprises, \\ kocsi.balazs@inf.unideb.hu \\ University of Debrecen, Faculty of Engineering, Department of Engineering Management and Enterprises, \\ budai.istvan@eng.unideb.hu
}

Abstract. The object of our work to increase production efficiency with the use of cost-efficient development tools at a Hungarian small enterprise. We apply data gathering techniques besides process modelling and diagnostic methods to reduce the total process time of the assembly process so as to induce cost reduction in the production. In this respect we investigate and rank root causes of wastes by cost-effective process development tools, like timebased FMEA (failure mode and effects analysis) as well as the 5 whys method. With the use of Monte-Carlo simulation companies can evaluate the change in the process, therefore, they can decide whether they want to carry out corrective measures or not. The accomplished changes can generate increasing competitive edge in the long run.

\section{Introduction}

According to the researches of Michael Porter, companies can choose between 3 major competitive strategies while they are creating their long-term strategy plan. They can decide in favour of differentiating their products or services which can result in higher prices for customers. The other choice can be based on cost leadership which means that the company focuses on reducing their cost which can lead to lower price-tags. And the third is a mixture of the first two strategies. To reach the second target, firms must supervise their business processes, and banish waste from them.

The company where we conducted our research had some problems in their process efficiency. It is due to the age of the company, because it was established 1 year ago, and until now they have not managed to organise and standardize their work. In addition, the company has to face growing demands, so it was high time to improve their assembly process. The object of the examination was an assembly process of cultivator.

\section{Product overview}

The main function of the cultivator machine is to scarify the ground and soil in grasslands, like football courts. With this technique the ground will have better waterways, and the grass will become stronger, 
because its roots can reach deeper. In Figure 1. the operation of the machine can be seen. The tines stick in the ground vertically, and the angular offset will alter with the drive of the tractor, and the ground will be aerated.

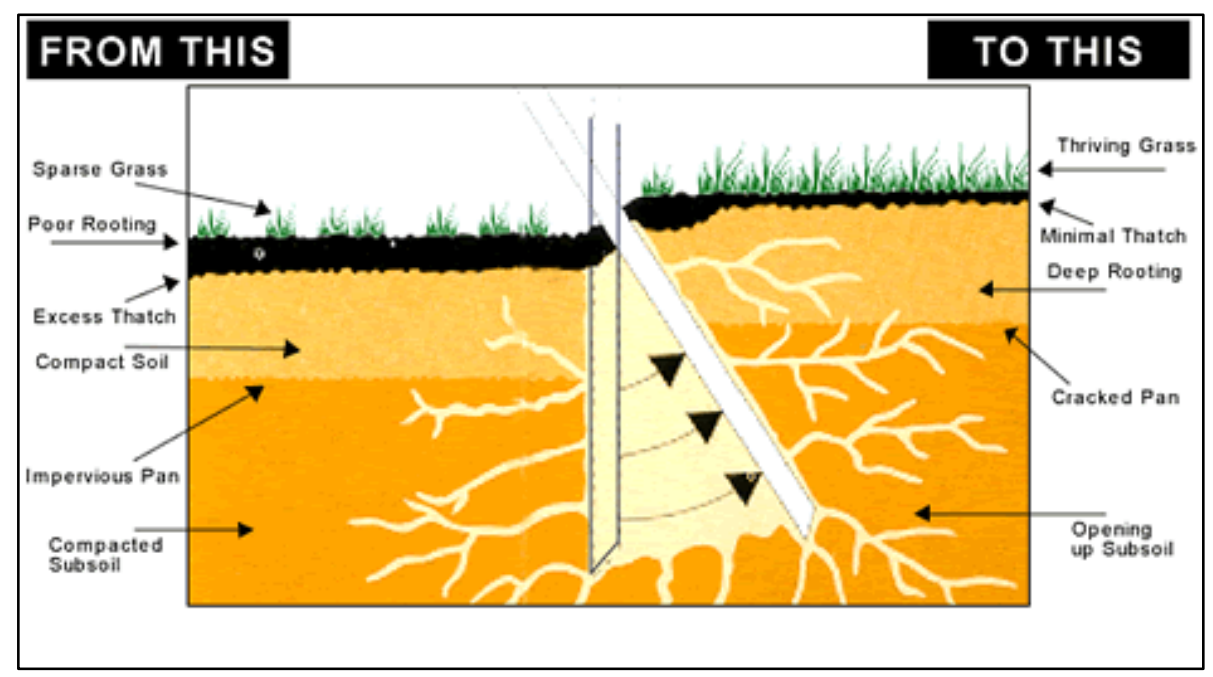

Figure 1. Mechanism of the cultivator machine, [P1]

\section{Literature background}

\subsection{Process simulation}

Modelling refers to the recognition of the properties of the real system, and make smaller and simplified version of the real life. The literature review differentiate 2 major types of models: there are theoretical and material models. Mathematical modelling is the part of the latter one, and it makes contact between the inputs, the process and outputs of the system through mathematical frame. This is the most applied modelling technique in engineering fields. [1]

Frequently used method next to the modelling technique is simulation, especially Monte-Carlo simulation, which was created by John Neumann in 1945. The Monte-Carlo simulation technique use random figures for define a state in real life, and the results of the simulations can be evaluated in a static way. The simulation is used to simulate the potential outputs and their probability of occurrence of different events, when the inputs are obscure. The simulation can results in a reliable output, if it is loaded several times, but nowadays thanks to the IT infrastructure, this can be easily accomplished [2]. Simulations have a lot of advantages in the Top-level managers' decision making system:

1. This method is very flexible, so any changes can be accomplished easily.

2. These changes have not an effect on real life system.

3. Complex simulation can also be handled by spreadsheet software and its plugins, so it is a costeffective way to analyze the effects of modifications in the process. 
Simulation methods are used in many fields, like modelling air pollution, drought, spread of pig farms' diseases [2].

If we try to simulate a process the result can be influenced by internal and external factors. We can give the distribution values of the affected process in theoritical or practical way. With the use of Monte-Carlo simulation a specific random process run can be acquired, with take into account the effects of the process, and calculate with reasonable random variables [3].

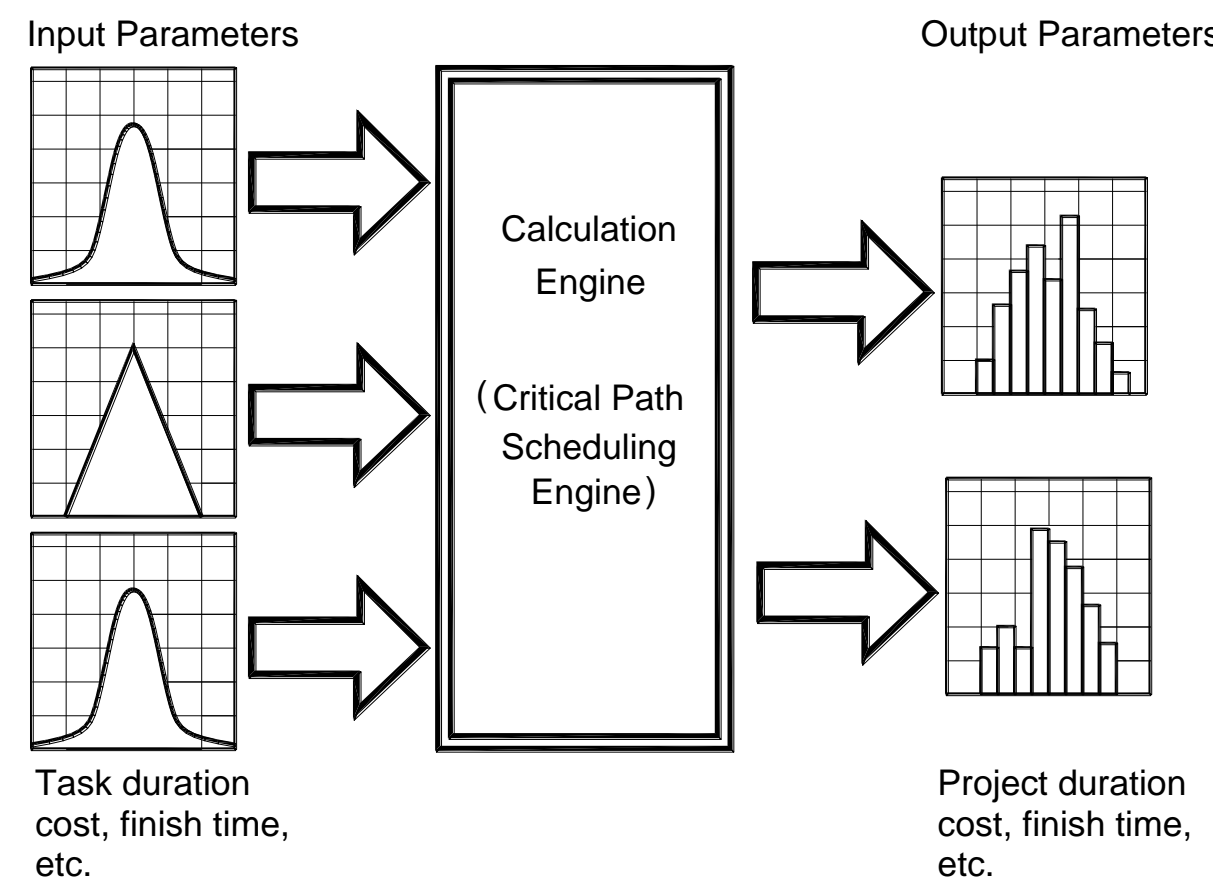

Figure 2. Monte-Carlo simulation's parameters

The simulation which is based on probabilities, tries to gain up the real life process run with artificially generated outputs, it creates the behaviour of the examined entity on a matemathical and statistical basis [4]. 


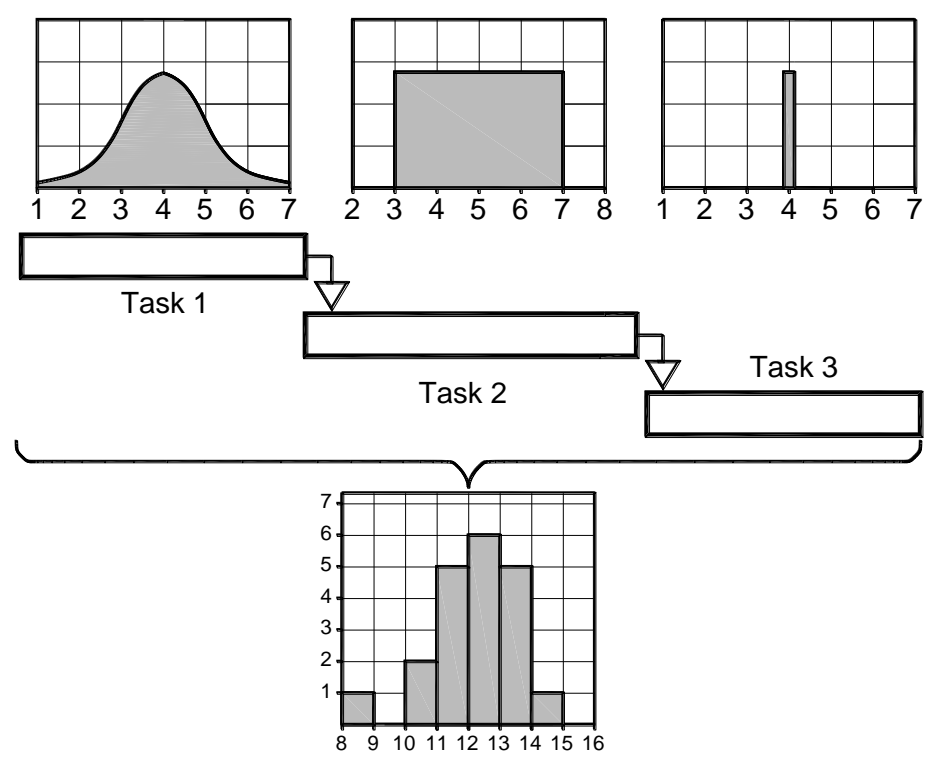

Figure 3. Monte-Carlo simulation's variety of distribution

\subsection{Failure Mode and Effects Analysis}

Failure Mode and Effects Analysis is invented for measure and evaluate the problems and their effects on the output. It was created by NASA in 1920s. 50 years later in the 1970s Ford Motor Company started using this method, and it has become an essential tool in quality-, project-, and product management fields in the company. [5]

This is a collective problem evaluating technique, and its aim is to score the problems from 1 to 10 by seriousness (S), occurrence (O) and detectability (D):

$$
R P N=S * O * D
$$

This means that the problem which has higher Risk Priority Number (RPN), that problem has a more crucial impact in the product or process quality. Limit can be established for dealing with those problems which worth the effort [6].

In this project we used a modified version of Failure Mode and Effects Analysis. Instead of counting by means of seriousness and detectability, we calculated RPN by multiplying probability of occurrence and estimated waste time:

$$
R P N=\text { Probability of occurence } * \text { Estimated waste time }
$$

\subsection{Event-driven Process Chain Diagram}

The event-driven process chain diagram is a good modelling technique for representing business processes. This is a good method to demonstrate the operational sequence of business workflows. Many resources (documents, data, organizations, etc.) can be easily assigned to elements of the process, and these help people to get to know their procedures better. [7] 
Four objects are defined and used in this modelling technique:

- Functions: Functions are those activities and tasks that usually add value to the business. They require inputs, consume resources and create outputs.

- Events: Event is a condition or state, which is caused by a function (post-condition), or it can be a requirement to start a function (pre-condition). These events change as the process changes. According to Mendling et al. this kind of object must be placed at the beginning and at the end of the flow [8].

- Rules: Three types of rules are differentiated in the EPC modelling technique. These rules create new paths in the process and help describe the real business processes better. The use of rules and logical connections between the activities can be clearly seen on the chart. These logical connections can be "or", "xor" and "and". These connectors have different effects on the process running.

- Resources: Real process flows do not consist only of events, functions and rules. Resources are necessary so that activities can be executed. For example, a database is essential to maintain inventory management properly.

\section{Empirical research plan}

\subsection{Research model}

We differentiated dependent and independent variables in our research. As seen in Figure 4., the independent variable is the total process time, while the dependent variable is the efficiency of the production process. We set up a research question: If we reduce total process time of the assembly process, will the efficiency of the process increase? In connection with the research question our hypothesis is that if we manage to reduce total process time, the efficiency of the assembly process will increase.
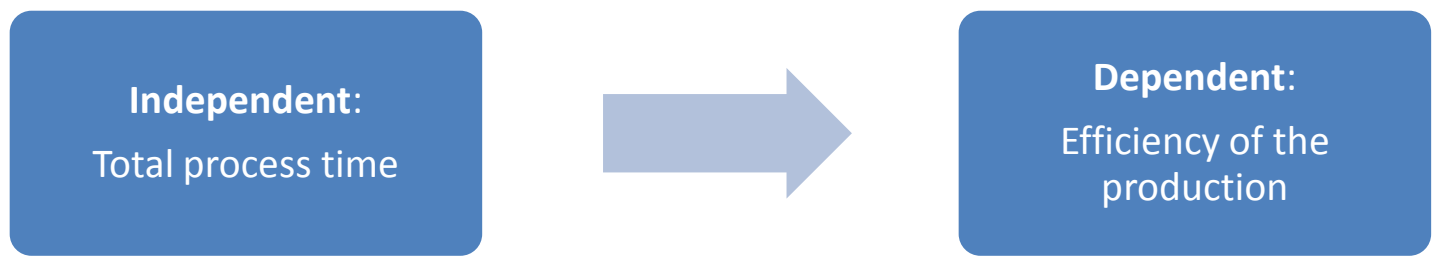

Figure 4. Research model

\subsection{Conceptualization}

1. Total process time (TPT): Required time, which is necessary to fabricate the product.

2. Activity: Continuous and regular action in manufacturing. Business processes consist of these activities.

3. Process: Chain of activities, which results in processed product. 
4. Simulation: The simulation is an experiment, and its aim is to transform the real process into a mathematic model, which can give reliable results through a well-considered planning.

5. Process improvement: Making processes more efficient from particular aspects, for instance: better quality, reduced lead time, cost-efficiency, etc.

\subsection{Operationalization}

In this work we established an input-output model, where we used the inputs listed below, and with the help of Monte-Carlo simulation we got the outputs. These outputs will serve as a confirmation or rejection of our research hypothesis and it also helped to evaluate the effectiveness of the corrective actions and which of them would worth accomplishing. At the company's request, we published the values, measurements and results in a distorted way.

\section{Inputs}

- Logical connection of the activities

- Minimum time of activities

- Maximum time of activities

- Probability distribution of activities

- The probability of activities and wastes

\section{Outputs}

- Total process time of the assembly process

\section{Data gathering}

- Duration of the investigation: $4^{\text {th }}$ October, $2016-18^{\text {th }}$ November 2016.

- Identification of activities, with at least 5 measurements

- Waste-investigation

- Estimates and discussions with top-level managers as well as operators

\section{Dana analysis}

- Time-based Failure and Mode Effects Analysis

- $\mathrm{ABC}$ classification

- 5 whys and other quality improvement methods carried out by a team

- Monte-Carlo simulation

\section{Applied software}

- Microsoft Excel

- ARIS express

During our research we got the opportunity to study the whole assembly process, talk with operators and top-level managers too, and we also helped with the assembly work. Then we identified all the 
actions, measured the time of the actions, the latter figures served as an input for simulation about the former process, and after that we created the Event-driven process chain diagram. The next step was to explore the wastes collectively, evaluate wastes by time-based FMEA and rank them with ABCanalysis. The next stage in the sequence was to make up corrective actions with the help of quality improvement methods such as collective brainstorming, 5 whys, and to prepare new EPC diagrams and simulations for the new processes. In the last part of the study we evaluate the results.

\section{Result}

\subsection{Former Process}

During our investigation the company got a purchase order for 25 machines. We identified 6 preassembly activities which were running sequentially. There were additional 15 sequentially running assembly activities. The pre-assembly work was accomplished by people who could not start or continue their assembly work because of a delay in the raw material delivery.

After the process investigation phase, we identified 26 different wastes in the whole business process. These wastes generates waits, unnecessary transports and overprocesses. These take time, consume resources (mainly human resources), so they are responsible for the effectiveness of the assembly line. Of course, some wastes have low incidence rate, but if it appears, it has a big impact on the total process time. For example, if the supplier cannot deliver in time, the whole assembly process must be stopped, which means loss of time, and operators must be hurry to make up for this fallback which must go detriment of quality.

After measuring all workstation's cycle time at least 5 times, we created our simulation of the process. The next step was to split the cycle times of every single activity into value-added and non-valueadded parts. The inputs were the minimum and maximum cycle times of the workstations. According to our measurements and the estimates of the operators, we calculated with normal density:

$$
E(T P T)=\Sigma\left(\Upsilon_{i} * \text { Expected cycle time } * P(i)\right)
$$

where:

$E(T P T)=$ Expected value of the total process time

$\Upsilon_{i}=$ random figure between 0 and 1

$P(i)=$ Probability of the occurrence of a particular activity

We loaded our simulation 10.000 times, and we got 10.000 values about total process time. Activities which was necessary in the assembly production got 1 probability number. The non-value added parts got a figure between 0 and 1, depended on the probability of the occurrence. These numbers based on professional estimates and observations. Then we calculated descriptive statistics of the main attributes. The outcome can be seen on Table $1 .$. 
Average total process Standard deviation of time total process time

\section{Confidence level}

$4.744 \mathrm{tmu}$

0.93

Estimated total

process time

Table 1. components of Total Process Time

51.306 tmu

The estimated total process time was 51.306,21 time measurement unit (tmu), which is very close to the real life value, so we did not encountered any barrier to continue our research.

\subsection{Improved processes}

The next step was to making corrective actions to banish the wastes from the assembly process. When we identified the non-value added actions, we evaluate them with a modified version of failure mode and effects analysis. This is called time-based FMEA, and we calculated risk priority numbers of the wastes by multiply probability of occurrence with estimated time loss. Thus we can give numbers to the problems, so we could ranked it with $\mathrm{ABC}$-analysis.

Then we made 2 categories from the non-value added activities:

- Internal wastes: wastes that was generated within the process, the company had an influence to solve them.

- External wastes: the supplier was responsible to these wastes, this is not impressionable directly by the company.

As these methods finished, we created a big group and tried to make a lot of corrective actions for the revealed wastes. At first, the group wanted to solve that problems that was in the category " $A$ " and " $B$ " in the $\mathrm{ABC}$-analysis, but then every single waste got a corrective action.

This means that we could make 3 alternative simulations: the first one was the total process without internal waste, the second was the assembly line without external process, and least the total process without revealed wastes.

In the practice it does not mean that we set the probability of occurrence to 0 , where we could make corrective actions. This means that there were some activities where the non-value added part's occurrence changed to 0 , but in some cases (especially at external wastes) this number was reduced.

Then we done the simulation with the formula mentioned the previous chapter. To get comparable results, we also loaded these 3 simulations 10.000 times one by one, and calculated the same statistics then Table 1. The results are summarized in Table 2.

\begin{tabular}{cc|ccc}
\hline & $\begin{array}{c}\text { Average total } \\
\text { process time }\end{array}$ & $\begin{array}{c}\text { Standard deviation } \\
\text { of total process } \\
\text { time }\end{array}$ & $\begin{array}{c}\text { Confidence } \\
\text { level }\end{array}$ & $\begin{array}{c}\text { Estimated total } \\
\text { process time }\end{array}$ \\
\cline { 2 - 5 } Without internal & $37.310 \mathrm{tmu}$ & $3.833 \mathrm{tmu}$ & 0.93 & $42.967 \mathrm{tmu}$ \\
\cline { 2 - 5 } & & &
\end{tabular}




\begin{tabular}{|c|c|c|c|c|}
\hline wastes & & & & \\
\hline $\begin{array}{c}\text { Without external } \\
\text { wastes }\end{array}$ & $27.883 \mathrm{tmu}$ & $1.781 \mathrm{tmu}$ & 0.93 & $30.512 \mathrm{tmu}$ \\
\hline $\begin{array}{l}\text { Without both } \\
\text { wastes }\end{array}$ & $21.489 \mathrm{tmu}$ & $1.309 \mathrm{tmu}$ & 0.93 & $23.422 \mathrm{tmu}$ \\
\hline
\end{tabular}

Table 2. Improved processes Total Process Times

\section{Conclusion}

According to the results of the simulations, we can confirm our hypothesis, that is, the efficiency of the assembly process can be increased if the total process time of the assembly line is reduced. This means that the company can prepare their products in less time if some of the wastes are removed from the process. Therefore, the company will be able to cope with the increased demand.

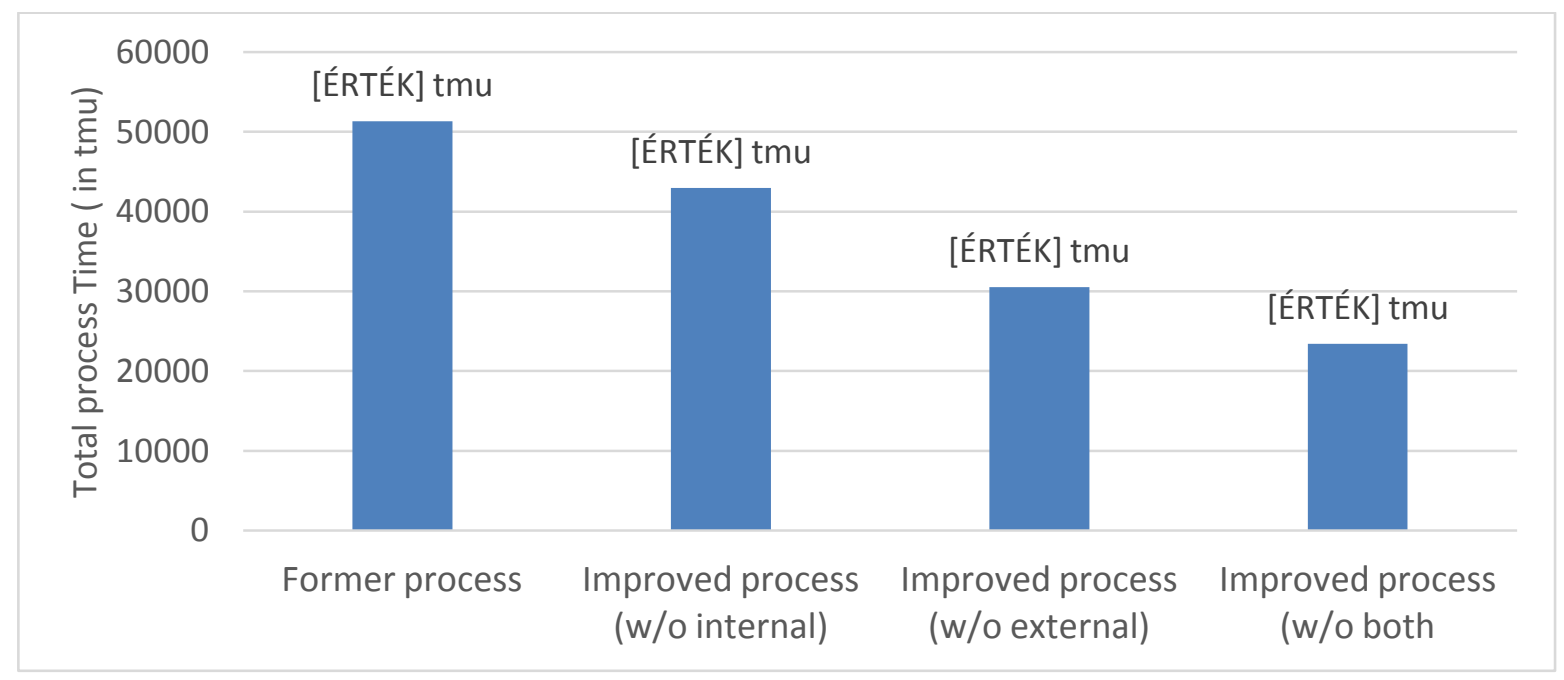

Figure 5. Compare of Total process times

As Figure 5. shows, if the company could eliminate internal wastes, $16.25 \%$ of the total process time decrease could be reached. If the firm could get rid of external wastes, we could detect $40.51 \%$ decrease in the total process time. If the company managed to banish all the wastes, the new total process time would account for $45.65 \%$ of the former total process time.

The former process took about 2 working days in reality. With the application of improvements, the company could speed up their assembly process to less than 1 working day.

\section{References}

[1] Pokorádi László, Rendszerek és folyamatok modellezése, Campus Kiadó, 25. 
[2] Gal T, Nagy L, David L, Vasa L, Balogh P Technology planning system as a decision support tool for dairy farms in Hungary ACTA POLYTECHNICA HUNGARICA 10:(8) pp. 231-244. (2013)

[3] Szobol, I. M. (1981): A Monte-Carlo módszerek alapjai. Műszaki Könyvki-adó, Budapest, 1981, ISBN: $963103819 \mathrm{X}$

[4] WEIHUA, Y. - CONG, T. (2012): Monte-Carlo simulation of information system project performance. System Engineering Procedia. 3. pp. 340-345.

[5] N. Sellappan - R. Sivasurbramanian: Modified Method for Evaluation of Risk Priority Number in Design FMEA, The Icfai Journal of Operations Management, Vol VII. No 1., 1-11.

[6] STAMATIS, D. H. (2003): Failure Mode Effect Analysis: FMEA from theory to execution. American Society for Quality. Quality Press, Milwaukee

[7] ariscommunity.com: Event-driven process chain (EPC) http://www.ariscommunity.com/event-driven-process-chain

[8] MENDLING, J. - REIJERS, H. A. - VAN DER AALST, W. M. P. (2010): Seven process modeling guidelines (7PMG). Information and Software Technology. 52.2. pp. 127-136.

[P1] Figure 1. Mechanism of the cultivator machine, http://www.bourneamenitysport.com/assets/images/verti-drain-diagram.gif 